\title{
A review of interventions to improve clinical outcomes following hospitalisation for heart failure
}

\author{
Harriette G.C. Van Spall ${ }^{1}$, Mamas A. Mamas ${ }^{2}$ \\ 'Division of Cardiology, Department of Medicine, Population Health Research Institute, McMaster University, Ontario, Canada \\ ${ }^{2}$ Keele Cardiovascular Research Group, Centre for Prognosis Research, Institute of Primary Care and Health Sciences, Keele University, United Kingdom
}

\begin{abstract}
A bstract
Heart failure (HF) is a leading cause of hospitalisation and death among older adults in high-income countries. HF is often accompanied by comorbid conditions, and patients hospitalised for HF commonly die or are readmitted in the weeks following hospital discharge. The objectives of this paper are to discuss the burden of HF hospitalisations in healthcare systems and to review strategies that reduce hospitalisations and death in this condition.
\end{abstract}

Key words: heart failure, hospitalisation, medication

Kardiol Pol 2019; 77, 3: 341-346

\section{INTRODUCTION}

Heart failure (HF) is one of the most common causes of hospitalisation in older adults and accounts for more than 1 million hospitalisations in Europe each year [1-3]. Disproportionately burdening the elderly, $\mathrm{HF}$ affects about $10 \%$ of men and $8 \%$ of women over the age of 60 years [2]. With increments in age, the proportion of hospitalisations for HF increases relative to hospitalisations for other diagnoses (Fig. 1) [3]. The five-year mortality is approximately $50 \%$ higher than that of many cancers [4]. With advances in medical and device therapy, the age-adjusted death rate has declined and the mean age at death from HF has risen, leaving a larger proportion of patients living with advanced HF [5-8]. The importance of implementing evidence-informed interventions to improve the quality of life and decrease avoidable hospitalisations has never been greater.

\section{EPIDEMIOLOGY}

Patients hospitalised for HF are at high risk of death and readmission, and approximately $25 \%$ of HF patients are rehospitalised within a month of discharge [9, 10]; readmission rates fairly static over the past decade in some national registries [11]. Hospitalisations and readmissions account for $70 \%$ of the direct healthcare costs in HF in high-income countries [12]. About half of all readmissions are due to worsening HF and the other half due to comorbidities such as kidney disease and diabetes [13-20]. Functional limitation, frailty, psychosocial and socioeconomic factors limiting adherence to medications, self-monitoring, and follow-up may also impact the overall readmission rate [21-23].

There are two high-risk periods following hospitalisation for HF: one is the transitional care period (one to two months after hospital discharge), when patients face a $25 \%$ risk of readmission, and the other is during the last two months of life, when the risk of readmission increases to 50\% [24]. The period between these two is the plateau phase, a period of relative stability, when patients are at a $15 \%$ risk of readmission [24]. It is estimated that at least $25 \%$ of early HF readmissions within the first post-discharge month may be avoided through optimisation of care [25].

\section{STRATEGIES TO IMPROVE OUTCOMES AFTER HOSPITALISATION FOR HF}

There has been steady progress in the development of therapies for HF, with interventions that address the underlying causes of HF (e.g. coronary revascularisation, heart valve replacement, treatment of cardiomyopathies, etc.); drugs that decrease death and readmission; cardiac resynchronisation therapy (CRT) and implantable cardioverter-defibrillators (ICDs) that decrease death and also readmissions for selected patients; and mechanical circulatory support or transplant for a small subset of patients with HF. The use of healthcare

Address for correspondence:

Harriette G.C. Van Spall, MD, MPH, FRCPC, David Braley Research Institute Bldg, 20 Copeland Avenue, Suite C3-117, Hamilton ON L8L 0A3, Canada,

tel: (905) 521-2100 X40601, fax: (905) 297-3785, e-mail: Harriette.VanSpall@phri.ca

Received: 21.02.2019 Accepted: 21.02.2019 Available as AoP: 27.02.2019

Kardiologia Polska Copyright (c) Polish Cardiac Society 2019 


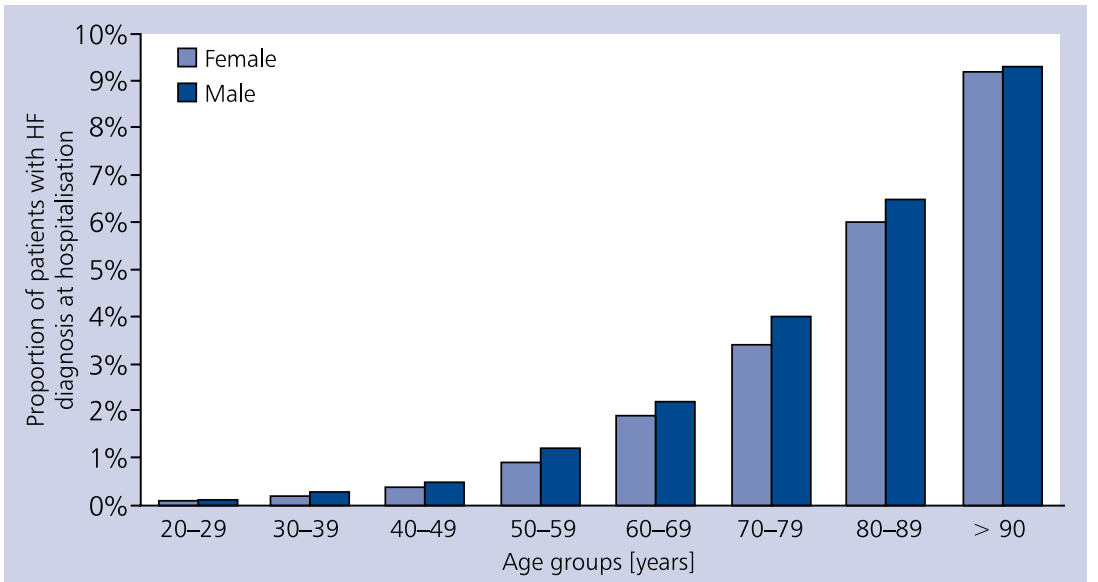

Figure 1. Proportion of hospitalisations due to heart failure (HF), stratified by age and sex (modified from [3])

services that are evidence-informed is an underemphasised but equally important strategy in decreasing death and readmission [26-38].

\section{Medical therapies}

Heart failure is classified according to left ventricular ejection fraction (LVEF) as reduced ( $<40 \%$ ), preserved $(>50 \%)$, or mid-range (40\%-50\%). In randomised controlled trials (RCTs), $\beta$-blockers as a class result in significant reductions in death in $\mathrm{HF}$ with reduced ejection fraction (HFrEF). The COMET trial demonstrated that carvedilol was superior to metoprolol in patients with LVEF $<35 \%$, who had been treated optimally with diuretics and angiotensin-converting enzyme inhibitors (ACEIs) [26]. All-cause mortality after a mean duration of $58 \pm 6$ months was $34 \%$ in patients receiving carvedilol (target dose, $25 \mathrm{mg}$ twice daily) and $40 \%$ in those treated with metoprolol (target dose, $50 \mathrm{mg}$ twice daily) (hazard ratio [HR] $0.83 ; 95 \%$ confidence interval $[\mathrm{Cl}] 0.74-0.93)$, with mortality benefit driven by a reduction in cardiovascular death. The incidence of adverse effects and drug withdrawals did not differ between the two study groups.

There have been no other head-to-head comparisons of $\beta$-blockers in HFrEF. A pairwise network meta-analysis of mainly indirect comparisons of $\beta$-blockers demonstrated mortality benefits compared with placebo after a median of 12 months (odds ratio $0.69 ; 95 \% \mathrm{Cl} 0.56-0.80$ ), with no significant differences between $\beta$-blockers for the risk of death, sudden cardiac death, death due to pump failure, or drug discontinuation [27]. This meta-analysis showed that among $\beta$-blockers, carvedilol demonstrated the greatest reduction in mortality among HF patients, and also had the best tolerability, although not significantly different from other $\beta$-blockers. Among the $\beta$-blockers tested, carvedilol, bisoprolol, and sustained-release metoprolol had the widest range of clinical applications, so these three specific $\beta$-blockers are recommended as first-line therapy in patients with HFrEF.
Angiotensin-converting enzyme inhibitors are widely used in HF. Several RCTs have demonstrated risk reduction in both mortality and HF readmission. An individual patient data meta-analysis [28], including more than 11,000 patients randomly assigned to treatment or placebo and followed for an average of 35 months, showed that ACEls significantly decreased both mortality and readmission risk. The benefits were observed early after the initiation of therapy, persisted long-term, and were largely independent of age, sex, and use of diuretics, acetylsalicylic acid, and $\beta$-blockers. There was a trend towards a greater reduction in the risk of death or HF readmission in patients with lower ejection fractions [29].

The benefit of angiotensin receptor-neprilysin inhibitors (ARNIs) was demonstrated in PARADIGM-HF, an RCT that randomised patients with HFrEF and New York Heart Association (NYHA) class II-IV to sacubitril/valsartan $200 \mathrm{mg}$ twice daily or enalapril $10 \mathrm{mg}$ twice daily, in addition to recommended therapy [28]. The primary outcome was a composite of death from cardiovascular causes or hospitalisation for HF. After a median follow-up of 27 months, the primary outcome occurred in $21.8 \%$ of patients from the sacubitril/valsartan arm and $26.5 \%$ in the enalapril arm (HR 0.80; 95\% Cl 0.73-0.87). The proportions of patients who died from any cause were $17.0 \%$ and $19.8 \%$, respectively (HR $0.84 ; 95 \% \mathrm{Cl} 0.76-0.93$ ), and from cardiovascular causes, $13.3 \%$ and $16.5 \%$, respectively (HR 0.80; 95\% Cl 0.71-0.89). Relative to enalapril, sacubitril/valsartan decreased the risk of hospitalisation for HF by $21 \%$ (HR $0.79 ; 95 \% \mathrm{Cl} 0.71-0.89)$. Adverse effects of sacubitril/valsartan were hypotension and angioedema, with lower proportions of renal impairment, hyperkalaemia, and cough compared with the enalapril group [29]. This class of agents is now recommended as second-line therapy instead of ACEls if patients with HFrEF are symptomatic on maximally tolerated doses of ACEIs. A recent RCT, PIONEER-HF, demonstrated the safety of initiating ARNIs during hospitalisation for acute decompensated HF, but while there was an improvement in 
the biomarker profile, the study was not statistically powered to detect a difference in clinical outcomes [30].

Several RCTs have demonstrated a decrease in death and hospitalisation with mineralocorticoid receptor antagonists (MRAs) in the setting of HFrEF, defined as an ejection fraction $<35 \%$ in these particular trials. This includes the RALES trial [31], in which spironolactone decreased all-cause death (HR 0.70; 95\% Cl 0.60-0.82); the EPHESUS trial [32], in which epleronone decreased all-cause death (relative risk [RR] 0.85; 95\% $\mathrm{Cl}$ 0.75-0.96); and the EMPHASIS trial [33], in which epleronone decreased the composite outcome of cardiovascular death or HF hospitalisation (HR 0.63; 95\% Cl 0.54-0.74).

Ivabradine is an inhibitor of the cardiac pacemaker $\mathrm{I}_{\mathrm{f}}$ current in the sinoatrial node, and it decreases the heart rate without reducing blood pressure [34]. The drug does not affect atrioventricular or intraventricular conduction times, myocardial contractility, or ventricular repolarisation [34]. The SHIFT trial [35] evaluated the efficacy of ivabradine in patients with HFrEF, classified as NYHA class II-IV. Patients were required to have normal sinus rhythm, a ventricular rate $>70 \mathrm{bpm}$, and hospitalisation in the preceding year. Patients on ivabradine had a significant reduction in the composite endpoint of death and HF hospitalisation (24\% in the ivabradine group and $29 \%$ in the placebo group; HR 0.82; 95\% Cl 0.75-0.90), but this was driven mainly by a reduction in HF hospitalisation ( $16 \%$ vs. $21 \%$, respectively; HR $0.74 ; 95 \%$ Cl $0.66-0.83$ ) [35]. Therefore, there is a class Ila indication for the use of ivabradine in patients who are symptomatic with HFrEF, once they have been optimised on ARNIs, $\beta$-blockers, and MRAs.

In summary, it is recommended that all patients with HFrEF be initiated and up-titrated on ACEls and $\beta$-blockers to their target doses, and diuretics to signs or symptoms of decompensation. For patients who are still symptomatic, it is recommended that MRAs be added and maintained at target doses. Those who remain symptomatic with NYHA class II or worse symptoms and reduced ejection fraction should be switched from ACEls to ARNIs. This requires a washout period of $36 \mathrm{~h}$ after cessation of ACEI therapy to prevent angioedema. The sacubitril component inhibits neprilysin, and this culminates in angioedema, particularly in patients who are on an ACEI. Contraindications to the use of ARNIs are a glomerular filtration rate $<30 \mathrm{~mL} / \mathrm{min}$, severe liver dysfunction, a history of angioedema, and hypotension with a systolic blood pressure $<90 \mathrm{mmHg}$. Patients should be monitored for hypotension, hyperkalaemia, and renal dysfunction. For those patients who are symptomatic on maximally tolerated doses of these medications and with a heart rate $>70 \mathrm{bpm}$, ivabradine could be considered as an add-on therapy, keeping in mind that this is only a class Ila recommendation based on a single RCT [36]. A primary prophylactic ICD should be considered in patients with an LVEF $<35 \%$ and NYHA class II-III symptoms despite optimal medical therapy for three months. In addition, patients who have normal sinus rhythm, a QRS duration of at least $150 \mathrm{ms,}$ and a left bundle branch block pattern on electrocardiography should be considered for CRT $[37,38]$.

Heart failure with preserved ejection fraction (HFpEF) is as prevalent as HFrEF but differs in the pathophysiology from HFrEF, with little evidence to date to support specific treatments $[39,40]$. Strategies include managing volume and addressing underlying risk factors including hypertension, atrial fibrillation, and obesity. The TOPCAT trial [41] demonstrated a reduction in HF hospitalisations with spironolactone in HFpEF. There is no evidence of harm with the use of classes of medications that have been proved effective in HFrEF, so in patients who are hypertensive, have ischaemic heart disease, or require rate control for atrial fibrillation, $\beta$-blockers, ACEls, and/or MRAs may be considered.

B-type natriuretic peptides (BNPs) can help detect decompensated HF. Rehospitalisation for HF is typically preceded by an elevation in left ventricular filling pressures that precede the clinical sequelae of HF by two to three weeks. BNPs are sensitive to perturbations in haemodynamics. The levels of cardiac biomarkers including natriuretic peptides and cardiac troponins may also predict readmission risk and guide titration of therapies to improve clinical outcomes [42-46]. However, the GUIDE-IT trial [47] did not show a reduction in HF hospitalisation or cardiovascular mortality among patients with HFrEF who received therapies titrated to biomarker levels.

\section{Healthcare services}

Healthcare services such as exercise training and cardiac rehabilitation have been shown to improve clinical outcomes in meta-analyses. A Cochrane systematic review of RCTs comparing exercise-based interventions to no exercise demonstrated a trend to decrease mortality in the long term with the use of exercise therapy (risk ratio $0.88 ; 95 \% \mathrm{Cl} 0.75-1.02$ ) [48]. Compared with control, exercise training reduced the rate of all hospitalisations (risk ratio $0.75 ; 95 \% \mathrm{Cl} 0.62-0.92$ ) and HF hospitalisation (risk ratio $0.61 ; 95 \% \mathrm{Cl} 0.46-0.80$ ) [48].

Transitional care services that bridge the gap as patients transition between healthcare settings and clinicians (from hospital to home) can also improve clinical outcomes. In a network meta-analysis of 54 RCTs that assessed the efficacy of transitional care services in patients hospitalised for HF, provided $\geq$ one month of follow-up, and reported all-cause mortality or all-cause readmissions [49], nurse home visits, disease management clinics, and nurse case management (a nurse-led initiative that begins in a hospital and continues through to the post-discharge phase) improved clinical outcomes relative to other services following hospital discharge [49]. Among services that significantly decreased all-cause mortality compared with usual care, nurse home visits were most effective (RR 0.78; 95\% Cl 0.62-0.98), followed by disease management clinics (RR 0.80; 95\% Cl 0.67-0.97). Among services that significantly decreased all-cause 
readmission, nurse home visits were most effective (incident rate ratio [IRR] $0.65 ; 95 \% \mathrm{Cl} 0.49-0.86)$, followed by nurse case management (IRR $0.77 ; 95 \% \mathrm{Cl} 0.63-0.95)$ and disease management clinics (IRR 0.80; 95\% Cl 0.66-0.97). Nurse home visits had the greatest pooled cost-savings [48]. How to practically implement these services within healthcare systems, however, is unclear. In a pragmatic stepped-wedge cluster randomised trial within a publicly funded healthcare system, a transitional care model combining self-care education, multidisciplinary care, and, among high-risk patients, post-discharge nurse-led home visits and outpatient care in disease management clinics, did not improve the primary outcome of time to composite all-cause death, readmission, or emergency department visits at three months (HR 0.99; $95 \% \mathrm{Cl} 0.83-1.19)$. However, it was associated with improved secondary patient-reported outcomes of discharge preparedness, quality of care, and quality of life $[50,51]$.

\section{Addressing advanced HF}

There is a sharp increase in the risk of HF admissions in the last 30-60 days before death. Retrospective data from 300,000 patients in Ontario, Canada revealed that the greatest cost of HF care occurs in the last months (six to eight weeks) of life. The care that is provided in hospitals is often discordant with patients' values and preferences. Recognising advanced or end-stage HF can help facilitate timely referral for mechanical circulatory support and transplant. Patients with advanced HF experience hypotension, require large doses of intravenous diuretics, and experience frequent defibrillator shocks, recurrent hospitalisations, intolerance to their guideline-based medical therapy, and progressive worsening of their functional status. Such patients may have a progressive decline in renal function and hyponatraemia. Among patients who do not qualify for these therapies and continue to deteriorate despite best evidence-informed invasive and medical-guided therapy, it is important to initiate conversations about values, preferences, and end-of-life care planning [52]. The latter should include a discussion regarding the patient's goals of care and palliative care interventions, such as deactivating ICDs so that patients do not experience refractory shocks, managing dyspnoea that may require opioid therapy, managing psychosocial and spiritual distress, implementing home care supports, and referring patients to a hospice, which is frequently inaccessible to patients with HF [53].

\section{Addressing comorbidities}

The burden of cardiac and non-cardiac comorbidities among patients hospitalised for HF has been under-recognised. While efforts to improve outcomes following hospitalisation for HF have traditionally focused on improving HF care, optimal management of the patient who has been hospitalised for HF requires integrated, multidisciplinary care to address comorbidities that account for half of all readmissions. Policies that pe- nalise institutions for readmissions following HF hospitalisation - in the absence of models of care that address both HF and its complex comorbidities in a manner that is patient-centred and clinically effective - are premature and unlikely to be successful in improving survival and quality of life.

\section{SUMMARY}

Approaches to improving outcomes in HF include: addressing the underlying cause; optimising medical therapies, which include diuretics, ACEls, $\beta$-blockers, MRAs, ARNIs, and in some patients ivabradine; considering CRT/ICD in candidates; optimising health services in the healthcare system, which may include rehabilitation or exercise therapy and transitional care services; referring selected patients to transplant or palliative care; and incorporating patients' values and preferences throughout the care continuum, and particularly near the end of life.

Funding/Conflict of interest: Harriette G.C. Van Spall receives funding from the Canadian Institutes for Health Research. She receives salary support from Ontario's Ministry of Health and Long-Term Care and Hamilton Health Sciences Research Award. She has received in-kind research funding and speakers' honoraria from Roche Diagnostics. Mamas A. Mamas declares no conflict of interest.

\section{References}

1. Stevenson LW, Pande R. Witness to Progress. Circulation. 2011; 4(4): 390-392, doi: 10.1161/circheartfailure.111.963066.

2. Roger V, Go A, Lloyd-Jones D, et al. Heart disease and stroke statistics-2012 update. Circulation. 2012; 125(1): e2-e220, doi: 10.1161/cir.0b013e31823ac046.

3. Dai S, Walsh P, Wielgosz A, et al. Comorbidities and mortality associated with hospitalized heart failure in Canada. Can J Cardiol. 2012; 28(1): 74-79, doi: 10.1016/j.cjca.2011.05.002, indexed in Pubmed: 21885240.

4. Askoxylakis V, Thieke C, Pleger ST, et al. Long-term survival of cancer patients compared to heart failure and stroke: a systematic review. BMC Cancer. 2010; 10: 105, doi: 10.1186/1471-2407-10105, indexed in Pubmed: 20307299.

5. Chen J, Normand SLT, Wang Y, et al. National and regional trends in heart failure hospitalization and mortality rates for Medicare beneficiaries, 1998-2008. JAMA. 2011; 306(15): 1669-1678, doi: 10.1001/jama.2011.1474, indexed in Pubmed: 22009099.

6. Levy D, Kenchaiah S, Larson MG, et al. Long-term trends in the incidence of and survival with heart failure. N Engl J Med. 2002; 347(18): 1397-1402, doi: 10.1056/NEJMoa020265, indexed in Pubmed: 12409541.

7. Jhund PS, Macintyre K, Simpson CR, et al. Long-term trends in first hospitalization for heart failure and subsequent survival between 1986 and 2003: a population study of 5.1 million people. Circulation. 2009; 119(4): 515-523, doi: 10.1161/CIRCULATIONAHA.108.812172, indexed in Pubmed: 19153268.

8. Laribi S, Aouba A, Nikolaou M, et al. Trends in death attributed to heart failure over the past two decades in Europe. Eur J Heart Fail. 2012; 14(3): 234-239, doi: 10.1093/eurihf/hfr182, indexed in Pubmed: 22237388.

9. Krumholz HM, Merrill AR, Schone EM, et al. Patterns of hospital performance in acute myocardial infarction and heart failure 30-day mortality and readmission. Circ Cardiovasc 
Qual Outcomes. 2009; 2(5): 407-413, doi: 10.1161/CIRCOUTCOMES.109.883256, indexed in Pubmed: 20031870.

10. Chun S, Tu JV, Wijeysundera HC, et al. Lifetime analysis of hospitalizations and survival of patients newly admitted with heart failure. Circ Heart Fail. 2012; 5(4): 414-421, doi: 10.1161/CIRCHEARTFAILURE.111.964791, indexed in Pubmed: 22556322.

11. Shiraishi Y, Kohsaka S, Sato N, et al. 9-year trend in the management of acute heart failure in Japan: a report from the national consortium of acute heart failure registries. J Am Heart Assoc. 2018; 7(18): e008687, doi: 10.1161/JAHA.118.008687, indexed in Pubmed: 30371201.

12. Stewart S, Jenkins A, Buchan S, et al. The current cost of heart failure to the National Health Service in the UK. Eur J Heart Fail. 2002; 4(3): 361-371, indexed in Pubmed: 12034163.

13. Ambrosy AP, Fonarow GC, Butler J, et al. The global health and economic burden of hospitalizations for heart failure: lessons learned from hospitalized heart failure registries. J Am Coll Cardiol. 2014; 63(12): 1123-1133, doi: 10.1016/j.jacc.2013.11.053, indexed in Pubmed: 24491689.

14. Cowie MR, Anker SD, Cleland JGF, et al. Improving care for patients with acute heart failure: before, during and after hospitalization. ESC Heart Fail. 2014; 1(2): 110-145, doi: 10.1002/ehf2.12021, indexed in Pubmed: 28834628.

15. Butler J, Braunwald E, Gheorghiade M. Recognizing worsening chronic heart failure as an entity and an end point in clinical trials. JAMA. 2014; 312(8): 789-790, doi: 10.1001/jama.2014.6643, indexed in Pubmed: 25157719.

16. O'Connor CM, Miller AB, Blair JEA, et al. Causes of death and rehospitalization in patients hospitalized with worsening heart failure and reduced left ventricular ejection fraction: results from Efficacy of Vasopressin Antagonism in Heart Failure Outcome Study with Tolvaptan (EVEREST) program. Am Heart J. 2010; 159(5): 841-849.e1, doi: 10.1016/j.ahj.2010.02.023, indexed in Pubmed: 20435194.

17. Butler J, Chirovsky D, Phatak H, et al. Renal function, health outcomes, and resource utilization in acute heart failure. Circulation. 2010; 3(6): 726-745, doi: 10.1161/circheartfailure.109.920298.

18. Metra M, Davison B, Bettari L, et al. Is Worsening Renal Function an Ominous Prognostic Sign in Patients With Acute Heart Failure? Circulation. 2012;5(1): 54-62, doi: 10.1161/circhearffailure.111.963413.

19. Krumholz HM, Parent EM, Tu N, et al. Readmission after hospitalization for congestive heart failure among Medicare beneficiaries. Arch Intern Med. 1997; 157(1): 99-104, indexed in Pubmed: 8996046.

20. Felker GM, Leimberger JD, Califf RM, et al. Risk stratification after hospitalization for decompensated heart failure. J Card Fail. 2004; 10(6): 460-466, indexed in Pubmed: 15599835.

21. Flint KM, Matlock DD, Lindenfeld J, et al. Frailty and the selection of patients for destination therapy left ventricular assist device. Circ Heart Fail. 2012; 5(2): 286-293, doi: 10.1161/CIRCHEARTFAILURE.111.963215, indexed in Pubmed: 22438521.

22. Lewis EF. Beyond the $P$ value: The quest for improving health status in patients with ischemic heart disease. Circulation. 2010; 122(17): 1664-1666, doi: 10.1161/CIRCULATIONAHA.110.982041, indexed in Pubmed: 20937972.

23. Fonarow GC, Abraham WT, Albert NM, et al. OPTIMIZE-HF Investigators and Hospitals. Factors identified as precipitating hospital admissions for heart failure and clinical outcomes: findings from OPTIMIZE-HF. Arch Intern Med. 2008; 168(8): 847-854, doi: 10.1001/archinte.168.8.847, indexed in Pubmed: 18443260.

24. Desai AS, Stevenson LW. Rehospitalisation for heart failure: predict or prevent? Circulation. 2012; 126(4): 501-506.

25. van Walraven C, Bennett C, Jennings A, et al. Proportion of hospital readmissions deemed avoidable: a systematic review. CMAJ. 2011; 183(7): E391-E402, doi: 10.1503/cmaj.101860, indexed in Pubmed: 21444623.
26. Poole-Wilson PA, Swedberg K, Cleland JGF, et al. Comparison of carvedilol and metoprolol on clinical outcomes in patients with chronic heart failure in the Carvedilol Or Metoprolol European Trial (COMET): randomised controlled trial. Lancet. 2003; 362(9377): 7-13, doi: 10.1016/S0140-6736(03)13800-7, indexed in Pubmed: 12853193.

27. Chatterjee S, Biondi-Zoccai G, Abbate A, et al. Benefits of $\beta$ blockers in patients with heart failure and reduced ejection fraction: network meta-analysis. BMJ. 2013; 346: f55, doi: 10.1136/bmj.f55, indexed in Pubmed: 23325883.

28. Flather MD, Yusuf S, Køber L, et al. Long-term ACE-inhibitor therapy in patients with heart failure or left-ventricular dysfunction: a systematic overview of data from individual patients. ACE-Inhibitor Myocardial Infarction Collaborative Group. Lancet. 2000; 355(9215): 1575-1581, indexed in Pubmed: 10821360.

29. McMurray J, Packer M, Desai A, et al. Angiotensin-Neprilysin Inhibition versus Enalapril in Heart Failure. N Engl J Med. 2014; 371(11): 993-1004, doi: 10.1056/nejmoa1409077.

30. Velazquez EJ, Morrow DA, DeVore AD, et al. Angiotensin-Neprilysin inhibition in acute decompensated heart failure. N Engl J Med. 2019; 380(6): 539-548, doi: 10.1056/NEJMoa1812851, indexed in Pubmed: 30415601.

31. Pitt B, Zannad F, Remme W, et al. The effect of spironolactone on morbidity and mortality in patients with severe heart failure. N Engl J Med. 1999; 341(10): 709-717, doi: 10.1056/nejm199909023411001.

32. Pitt B, Remme W, Zannad F, et al. Eplerenone, a selective aldosterone blocker, in patients with left ventricular dysfunction after myocardial infarction. N Engl J Med. 2003; 348(14): 1309-1321, doi: 10.1056/NEJMoa030207, indexed in Pubmed: 12668699.

33. Zannad F, McMurray JJV, Krum H, et al. Eplerenone in patients with systolic heart failure and mild symptoms. N Engl J Med. 2011; 364(1): 11-21, doi:10.1056/NEJMoa1009492, indexed in Pubmed: 21073363.

34. Perry CM. Ivabradine: in adults with chronic heart failure with reduced left ventricular ejection fraction. Am J Cardiovasc Drugs. 2012; 12(6): 415-426, doi: 10.2165/11209990-00000000000000, indexed in Pubmed: 23181944.

35. Swedberg K, Komajda M, Böhm M, et al. Ivabradine and outcomes in chronic heart failure (SHIFT): a randomised placebo-controlled study. Lancet. 2010; 376(9744): 875-885, doi: 10.1016/S01406736(10)61198-1, indexed in Pubmed: 20801500.

36. Ponikowski P, Voors AA, Anker SD, et al. 2016 ESC Guidelines for the diagnosis and treatment of acute and chronic heart failure: The Task Force for the diagnosis and treatment of acute and chronic heart failure of the European Society of Cardiology (ESC) Developed with the special contribution of the Heart Failure Association (HFA) of the ESC. Eur Heart J. 2016; 37(27): 2129-2200, doi: 10.1093/eurheartj/ehw128, indexed in Pubmed: 27206819.

37. Yancy CW, Jessup M, Bozkurt B, et al. 2013 ACCF/AHA guideline for the management of heart failure: a report of the American College of Cardiology Foundation/American Heart Association Task Force on Practice Guidelines. J Am Coll Cardiol. 2013; 62(16): e147-239.

38. Priori SG, Blomström-Lundqvist C, Mazzanti A, et al. 2015 ESC Guidelines for the management of patients with ventricular arrhythmias and the prevention of sudden cardiac death: The Task Force for the Management of Patients with Ventricular Arrhythmias and the Prevention of Sudden Cardiac Death of the European Society of Cardiology (ESC). Endorsed by: Association for European Paediatric and Congenital Cardiology (AEPC). Eur Heart J. 2015; 36(41): 2793-867.

39. Zheng S, Chan F, Nabeebaccus A, et al. Drug treatment effects on outcomes in heart failure with preserved ejection fraction: a systematic review and meta-analysis. Heart. 2017; 104(5): 407-415, doi: 10.1136/heartjnl-2017-311652. 
40. Van Spall HGC. Review: In HF with preserved EF, $\beta$-blockers reduced mortality; drug treatment overall did not. Ann Intern Med. 2017; 167(12): JC68, doi: 10.7326/ACPJC-2017-167-12-068, indexed in Pubmed: 29255858.

41. Pitt B, Pfeffer M, Assmann S, et al. Spironolactone for Heart Failure with Preserved Ejection Fraction. N Engl J Med. 2014; 370(15): 1383-1392, doi: 10.1056/nejmoa1313731.

42. Kociol R, Horton J, Fonarow G, et al. Admission, discharge, or change in B-type natriuretic peptide and long-term outcomes: data from Organized Program to Initiate Lifesaving Treatment in Hospitalized Patients with Heart Failure (OPTIMIZE-HF) linked to Medicare claims. Circulation. 2011; 4(5): 628-636, doi: 10.1161/circheartfailure.111.962290.

43. Masson S, Anand I, Favero C, et al. Serial measurement of cardiac troponin $\mathrm{T}$ using a highly sensitive assay in patients with chronic heart failure: data from 2 large randomized clinical trials. Circulation. 2012; 125(2): 280-288, doi: 10.1161/CIRCULATIONAHA.111.044149, indexed in Pubmed: 22139751.

44. Allen LA, Gheorghiade M, Reid KJ, et al. Identifying patients hospitalized with heart failure at risk for unfavorable future quality of life. Circ Cardiovasc Qual Outcomes. 2011; 4(4): 389-398, doi: 10.1161/CIRCOUTCOMES.110.958009, indexed in Pubmed: 21693723

45. Troughton RW, Frampton CM, Brunner-La Rocca HP, et al. Effect of B-type natriuretic peptide-guided treatment of chronic heart failure on total mortality and hospitalization: an individual patient meta-analysis. Eur Heart J. 2014; 35(23): 1559-1567, doi: 10.1093/eurheartj/ehu090, indexed in Pubmed: 24603309 .

46. Van Spall HGC. ACP Journal Club. Review: Natriuretic peptide-guided therapy reduces mortality more than clinically guided therapy in heart failure. Ann Intern Med. 2014; 161(4):
JC10, doi: 10.7326/0003-4819-161-4-201408190-02010, indexed in Pubmed: 25133377.

47. Felker GM, Anstrom KJ, Adams KF, et al. Effect of Natriuretic Peptide-Guided Therapy on Hospitalization or Cardiovascular Mortality in High-Risk Patients With Heart Failure and Reduced Ejection Fraction: A Randomized Clinical Trial. JAMA. 2017; 318(8): 713-720, doi: 10.1001/jama.2017.10565, indexed in Pubmed: 28829876.

48. Taylor R, Sagar V, Davies E, et al. Exercise-based rehabilitation for heart failure. Cochrane Database Syst Rev. 2014; 4: CD003331, doi: 10.1002/14651858.cd003331.pub4.

49. Van Spall HGC, Rahman T, Mytton O, et al. Comparative effectiveness of transitional care services in patients discharged from the hospital with heart failure: a systematic review and network meta-analysis. Eur J Heart Fail. 2017; 19(11): 1427-1443, doi: 10.1002/ejhf.765, indexed in Pubmed: 28233442.

50. Van Spall HGC, Lee SFu, Xie F, et al. Knowledge to action: Rationale and design of the Patient-Centered Care Transitions in Heart Failure (PACT-HF) stepped wedge cluster randomized trial. Am Heart J. 2018; 199: 75-82, doi: 10.1016/j.ahj.2017.12.013, indexed in Pubmed: 29754670.

51. Van Spall HGC, Lee SF, Xie F, et al. Effect of Patient-Centered Transitional Care Services on Clinical Outcomes in Patients Hospitalized for Heart Failure: The PACT-HF Randomized Clinical Trial. JAMA. 2019; 321(8): 753-761; doi: 10.1161/jama.2019.0710.

52. Desai AS. Intensive management to reduce hospitalizations in patients with heart failure. Circulation. 2016; 133(17): 17041707, doi: 10.1161/CIRCULATIONAHA.115.017594, indexed in Pubmed: 27143153.

53. Allen LA, Stevenson LW, Grady KL, et al. Decision making in advanced heart failure: a scientific statement from the American Heart Association. Circulation. 2012; 125(15): 1928-1952, doi: 10.1161/CIR.0b013e31824f2173, indexed in Pubmed: 22392529.

Cite this aricle as: Van Spall HGC, Mamas MA. A review of interventions to improve clinical outcomes following hospitalisation for heart failure. Kardiol Pol. 2019; 77(3): 341-346, doi: 10.5603/KP.a2019.0039. 